\title{
PERANCANGAN ALAT PENGIRIS KERIPIK SINGKONG MENGGUNAKAN PENGGERAK MOTOR LISTRIK
}

\author{
Oleh : \\ Wirda Novarika AK., S.T.,M.M,; Ahmad Romadhon \\ Dosen Kopertis Wilayah I DPK STT Poliprofesi Medan; Mahasiswa Polsri
}

\begin{abstract}
Abstrack
Cassava is one of deligt provesion. In the other side nutrient contain and carbohidrate contain useful for the human body. Some food made by cassava such as : getok, kolak, tape crispy etc.Cassava chips is one of the most prefered snack by all people. Therefore to improve production and uniformity of the chips needed a tool. Researcher tried to make an economical cassava slice tool which can help the domestic industry to slicing the cassava chips.
\end{abstract}

\section{PENDAHULUAN}

\subsection{Latar Belakang Penelitian}

Karbohidrat merupakan zat yang sangat dibutuhkan oleh tubuh setiap manusia. Hal ini dikarenakan karbohidrat memiliki begitu banyak fungsi. Menjadi sumber energi untuk tubuh merupakan peran utama dari karbohidrat yang setiap gramnya mengandung kalori. Pada sistem sirkulasi darah di dalam tubuh manusia, sumber energi dihasilkan dari keberadaan karbohidrat yang berperan sebagai glukosa. karbohidrat tak hanya bisa didapatkan dari beras atau nasi yang menjadi makanan pokok yang telah kita kenal di Indonesia. Beberapa makananmakanan lainnya yang keberadaannya terlihat sangat sepele, ternyata juga memiliki kandungan karbohidrat yang sangat baik. Salah satu contohnya yaitu singkong.

Singkong dapat diolah menjadi berbagai macam (jenis) makanan. Aneka jenis makanan dari bahan makanan singkong antara lain, keripik, tape, getuk, kolak ubi, kelepon, bolu Ubi, dan opak. keripik merupakan salah satu cemilan yang sangat digemari oleh anakanak sampai orang dewasa. Dengan rasa renyah dan gurih serta rasa yang bermacam-macam membuat keripik singkong menjadi pilihan banyak

masyarakat sebagai camilan disaat santai maupun untuk menemani jalan-jalan.

Dilihat dari segi ekonomi, keripik singkong lebih mahal dari singkong yang belum diolah. Selain itu proses pembutannya pun mudah dilakukan, sehingga pengusaha kecil dapat dengan mudah untuk mengolahnya.

Setelah penulis amati, proses pembuatan kripik singkong dengan permesinan juga masih sangat sederhana. Prinsip kerjanya yaitu singkong dimasukkan kedalam mesin dengan menggunakan tangan dan pemotongan singkong dilakukan dengan menekan tuas pengiris. Sehingga hasil yang diperoleh belum optimal baik ditinjau dari jumlah produksi, kualitas, maupun efisiensi waktu. Dari kenyataan itulah penulis ingin menciptakan sebuah mesin pemotong singkong yang lebih praktis dan ekonomis dengan hasil produksi yang lebih banyak.

\subsection{Rumusan Masalah}

Berdasarkan latar belakang diatas rumusan masalah adalah bagaimana merancang alat pengiris keripik singkong menggunakan motor listrik. 


\subsection{Tujuan dan Manfaat}

Adapun tujuan pembuatan mesin Mesin Pengiris singkong dengan menggunakan motor listrik ini antara lain yaitu :

1. Untuk mendapatkan desain Mesin pengiris keripik singkong dengan menggunakan motor listrik.

2. Untuk mengetahui proses pembuatan Mesin pengiri ssingkong dengan menggunakan motor listrik.

3. Untuk mengetahui cara kerja Mesin Pemotong singkong dengan menggunakan motor listrik.

\section{HASIL DAN PEMBAHASAN}

\subsection{Perhitungan Daya Pada Motor}

Dik: $\mathrm{n} 1=$ Putaran motor

$$
=1400 \mathrm{rpm}
$$

Dp $=$ Diameter Pulley atas

$$
=20 \text { inchi }=457,2 \mathrm{~mm}
$$

$\mathrm{dp}=$ Diameter Pulley bawah

$$
=3 \text { inchi }=76,2 \mathrm{~mm}
$$

Dit: $\mathrm{n}_{2}=\ldots \ldots$ ?

Jawab:

$\frac{n_{1}}{n_{2}}=\frac{D_{p}}{d_{p}}$

$\frac{1400}{n_{2}}=\frac{457,2}{76,2}$

$n_{2}=\frac{106680}{457,2}$

$n_{2}=233,333 \mathrm{rpm}$

Jadi putaran yang didapat sebesar $233 \mathrm{rpm}$ Setelah melakukan pengujian, maka torsi pada poros dapat dihitung dengan rumus:

$$
\mathrm{T}=\mathrm{F} \cdot \mathrm{r}
$$

Ket : $\quad \mathrm{T}=$ torsi

$$
\begin{aligned}
\mathrm{F} & =\text { gaya potong } \\
& =9,89 \mathrm{~kg} \cdot 9 \cdot 81 \mathrm{~m} / \mathrm{s}^{2} \\
& =97,02 \mathrm{~N}
\end{aligned}
$$

\begin{tabular}{|c|c|c|c|}
\hline & 37,300 & & \multirow[t]{2}{*}{9.00} \\
\hline & 38,300 & & \\
\hline \multirow[t]{3}{*}{3} & 57,100 & \multirow{3}{*}{54,033} & \multirow{3}{*}{10.00} \\
\hline & 47,700 & & \\
\hline & 57,300 & & \\
\hline \multirow[t]{3}{*}{4} & 42,600 & \multirow{3}{*}{40,450} & \multirow{3}{*}{9.10} \\
\hline & 38,300 & & \\
\hline & 42,000 & & \\
\hline \multirow[t]{3}{*}{5} & 45,000 & \multirow{3}{*}{46,800} & \multirow{3}{*}{10.00} \\
\hline & 48,800 & & \\
\hline & 46,600 & & \\
\hline \multirow[t]{3}{*}{6} & 39,800 & \multirow{3}{*}{40,700} & \multirow{3}{*}{9.80} \\
\hline & 41,300 & & \\
\hline & 41,000 & & \\
\hline \multirow[t]{3}{*}{7} & 45,100 & \multirow{3}{*}{43,333} & \multirow{3}{*}{9.10} \\
\hline & 40,600 & & \\
\hline & 44,300 & & \\
\hline \multirow[t]{3}{*}{8} & 52,400 & \multirow{3}{*}{51,600} & \multirow{3}{*}{10.40} \\
\hline & 49,200 & & \\
\hline & 53,200 & & \\
\hline \multirow[t]{3}{*}{9} & 48,000 & \multirow{3}{*}{49,000} & \multirow{3}{*}{11.50} \\
\hline & 51,200 & & \\
\hline & 47,800 & & \\
\hline \multirow[t]{5}{*}{10} & 48,600 & \multirow{3}{*}{47,833} & \multirow{3}{*}{11.00} \\
\hline & 46,700 & & \\
\hline & 48,200 & & \\
\hline & & & \\
\hline & & & 9,89 \\
\hline
\end{tabular}

Putaran pada pulley $=233 \mathrm{rpm}(\mathrm{n} 2)$

Tabel 2.1 Hasil pengujian untuk mencari gaya potong

\begin{tabular}{|c|c|c|c|}
\hline No & $d(\mathrm{~mm})$ & $\operatorname{dr}(\mathrm{mm})$ & $\mathrm{f}(\mathrm{kg})$ \\
\hline 1 & 48,000 & & \multirow{2}{*}{4} \\
\cline { 1 - 2 } & 48,100 & 49,360 & \multirow{2}{*}{9.00} \\
\cline { 1 - 2 } & 51,980 & & \\
\hline 2 & 39,800 & 38,467 & \\
\hline
\end{tabular}

Setelah melakukan pengujian, maka torsi pada poros dapat dihitung dengan rumus:

$$
\mathrm{T}=\mathrm{F} \cdot \mathrm{r}
$$

Ket :

$$
\begin{aligned}
\mathrm{T} & =\text { torsi } \\
\mathrm{F} & =\text { gaya potong } \\
& =9,89 \mathrm{~kg} \cdot 9.81 \mathrm{~m} / \mathrm{s}^{2} \\
& =97,02 \mathrm{~N}
\end{aligned}
$$

Putaran pada pulley $=233 \mathrm{rpm}(\mathrm{n} 2)$

2.1.1 Torsi pada poros

$$
\begin{aligned}
\text { Torsi poros } & =\mathrm{F} \cdot \mathrm{r} \\
& =97,02 \mathrm{~N} .0,1286 \mathrm{~m} \\
& =12,476 \mathrm{Nm}
\end{aligned}
$$

2.1.2 Torsi pada motor

$$
\begin{aligned}
& \mathrm{T}_{\text {poros }} \cdot \mathrm{n}_{2}=\mathrm{T}_{\text {motor }} \cdot \mathrm{n}_{1} \\
& T_{\text {motor }}=\frac{12,76.233}{1400} \\
& \mathrm{~T}_{\text {motor }}=2,076 \mathrm{Nm}
\end{aligned}
$$


2.1.3 Daya pada motor

$P=\frac{T .2 \cdot \pi \cdot n}{60}$

$P=\frac{2,076 \cdot 2 \cdot \pi \cdot 1400}{60}$

$\mathrm{P}=304,278 \mathrm{Watt}$

$\mathrm{P}=0,407 \mathrm{hp}$

$\mathrm{P}_{\mathrm{d}}=\mathrm{P} . \mathrm{F}_{\mathrm{c}}$

$\mathrm{F}_{\mathrm{c}}=$ faktor koreksi

$=1,2$

$\mathrm{P}_{\mathrm{d}}=0,407.1,2$

$\mathrm{P}_{\mathrm{d}}=0,489 \mathrm{hp}$

Jadi daya motor yang akan digunakan yaitu $0,5 \mathrm{hp}$.

2.2 Perhitungan Pulley dan Sabuk

2.2.1 Perhitungan pulley

Dari perhitungan motor dan piringan di atas, didapat:

$\mathrm{N} 1=1400 \mathrm{rpm}$

$\mathrm{N} 2=233 \mathrm{rpm}$

$$
\frac{n 1}{n 2}=\frac{d 2}{d 1}
$$

$\frac{1400}{233}=\frac{d 2}{3}$

$\mathrm{d} 2=\frac{1400 \times 3}{233}$

$\mathrm{d} 2=18,02$ in $\cong 18$ in

\subsubsection{Perhitungan Sabuk}

Dik: Daya motor listrik $\left(\mathrm{P}_{\mathrm{d}}\right)$

$=373$ watt

Putaran motor listrik(n1)

$=1400 \mathrm{rpm}$

Putaran Piringan potong

$=233 \mathrm{rpm}$

Diameter pulley penggerak $\left(\mathrm{d}_{\mathrm{p}}\right)$

$=76,2 \mathrm{~mm}$

Diameter pulley yang digerakkan $\left(D_{p}\right)$ $=457,2 \mathrm{~mm}$

Jarak Sumbu poros yang direncanakan $=470 \mathrm{~mm}$

Sabuk yang digunakan dalam

perencanaan ini berfungsi untuk meneruskan putaran dari motor listrik keporos yang digerakan melalui pulley.

Atas dasar daya rencana dan putaran poros penggerak maka penampang sabuk V tersebut dapat dicari berdasarkan diagram dibawah ini.

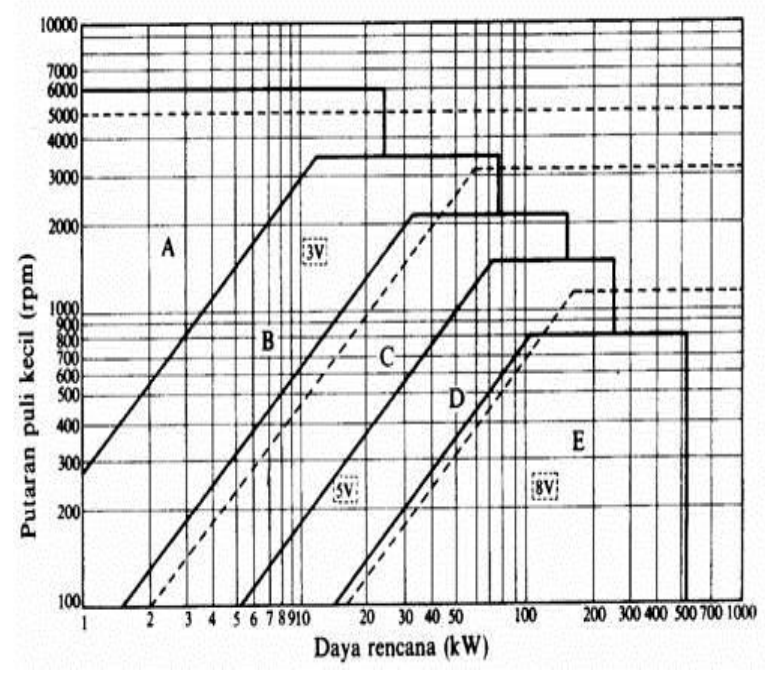

Gambar 2.1 Diagram Karpet

Sabuk-V

menentukan panjang sabuk :

$$
L=2 C+\frac{\pi}{2}(D+d)+\frac{1}{4 C}(D-d)^{2}
$$

Ket :

$\mathrm{L}=$ panjang sabuk

$\mathrm{C}=470 \mathrm{~mm}$

$\mathrm{D}=3 \mathrm{in}=76,2 \mathrm{~mm}$

$\mathrm{d}=18 \mathrm{in}=457,2 \mathrm{~mm}$

maka :

$$
\begin{aligned}
L=2.470 \mathrm{~m} & +\frac{\pi}{2}(76,2 \mathrm{~mm}+45,2 \mathrm{~mm}) \\
& +\frac{1}{4.470 \mathrm{~mm}}(76,2 \mathrm{~mm} \\
& -457,2 \mathrm{~mm})^{2} \\
& =940 \mathrm{~mm}+837,862 \mathrm{~mm}+77,213 \mathrm{~mm} \\
= & 1855,075 \mathrm{~mm} \\
= & 73,034 \mathrm{in} \cong 74 \mathrm{in}
\end{aligned}
$$

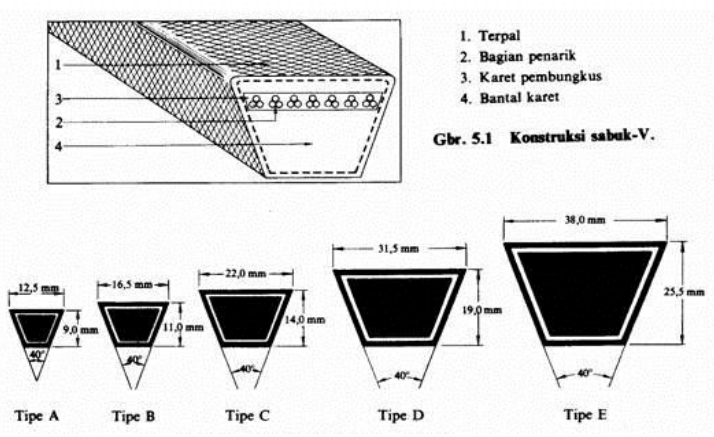

Gambar 2.2 Tipe Sabuk-V 
Dengan putaran motor $1400 \mathrm{rpm}$ dan daya $0,373 \mathrm{Kw}$ maka sabuk-V yang digunakan adalah sabuk- $\mathrm{V}$ tipe $\mathrm{B}$ dengan lebar $16,5 \mathrm{~mm}$ dan tebal $11 \mathrm{~mm}$.

\subsubsection{Luas penampang sabuk $A=t(b-t \tan 1 / 2 \alpha)$}

Ket :

$\mathrm{A}=$ Luas penampang

$\mathrm{t}=$ tebal sabuk

$\mathrm{b}=$ lebar sabuk

$\alpha=40^{\circ}$

$\mathrm{A}=11(16,5-11 \tan 1 / 240)$

$\mathrm{A}=11(16,5-11.0,363)$

$\mathrm{A}=11.12,507$

$\mathrm{A}=137,577 \mathrm{~mm}^{2}$

\subsubsection{Kecepatan linier sabuk}

Ket :

$$
V=\frac{\pi \cdot D 1 \cdot n 1}{60.1000}
$$

$\mathrm{V}=$ kecepatan linier sabuk $(\mathrm{m} / \mathrm{s})$

$\mathrm{D}_{\mathrm{p}}=$ diameter pulley pengerak $(\mathrm{mm})$

$\mathrm{N} 1=$ putaran motor listrik $(\mathrm{mm})$

$V=\frac{3,14 \cdot 76,2 \cdot 1400}{60 \cdot 1000}$

$\mathrm{V}=5,582 \mathrm{~m} / \mathrm{s}$

\subsubsection{Gaya tegang sabuk}

Ket :

$$
(T 1-T 2)=\frac{P}{V}
$$

$(\mathrm{T} 1-\mathrm{T} 2)=$ Tegangan sabuk kencang dikurang tegangan sabuk kendur $\mathrm{P}=$ daya yang ditransmisikan sabuk (watt) $\mathrm{V}=$ kecepatan linier sabuk $(\mathrm{m} / \mathrm{s})$

Maka :

$$
(T 1-T 2)=\frac{373 w a t t}{5,582 \mathrm{~m} / \mathrm{s}}
$$$$
(\mathrm{T} 1-\mathrm{T} 2)=66,821 \mathrm{~N} \ldots \ldots \text { pers. } 1
$$

Maka log untuk tegangan sabuk adalah :

$2,3 \log \frac{T 1}{T 2}=\mu \theta \operatorname{cosec} \alpha$

Dimana koefisien gesek pada pulley

$\mu=$ koefisiengesekpadapulley

$$
\begin{aligned}
\mu=0,54 & -\frac{66,821}{152,6+V} \\
\mu & =0,54-\frac{66,821}{152,6+5,582} \\
\mu & =0,54-0,422
\end{aligned}
$$

$$
\mu=0,118
$$

sudut kontak sabuk

$$
\begin{aligned}
& \theta=180-2 \cdot \arcsin \left(\frac{R-r}{C}\right) \\
& \theta=180-2 \cdot \arcsin \left(\frac{38,1-228,6}{470}\right) \\
& \theta=180-2 \cdot \arcsin -0,405 \\
& \theta=180+47,782 \\
& \theta=227,782^{0} \\
& \theta=3,97 \mathrm{rad}
\end{aligned}
$$

Sehingga :

$$
\begin{gathered}
2,3 \log \frac{T 1}{T 2}=\mu \theta \operatorname{cosec} \alpha \\
2,3 \log \frac{T 1}{T 2}= \\
0,118 \cdot 3,97 \operatorname{cosec} 20^{\circ} \\
2,3 \log \frac{T 1}{T 2}=0,118 \cdot 3,97.2,923 \\
\log \frac{T 1}{T 2}=0,595
\end{gathered}
$$$$
\mathrm{T} 1=3,935 \text {. } \mathrm{T} 2
$$
pers. 2

Maka dari pers. 1 dan pers. 2 didapat :

$$
\begin{gathered}
\mathrm{T} 1-\mathrm{T} 2=66,821 \mathrm{~N} \\
3,935 \mathrm{~T} 2-\mathrm{T} 2=66,821 \mathrm{~N} \\
\mathrm{~T} 2=\frac{66,821}{3,935-1} \\
\mathrm{~T} 2=22,766 \mathrm{~N} \\
\mathrm{~T} 1-\mathrm{T} 2=66,821 \mathrm{~N} \\
\mathrm{~T} 1-22,766 \mathrm{~N}=66,821 \mathrm{~N} \\
\mathrm{~T} 1=66,821 \mathrm{~N}+22,766 \mathrm{~N} \\
\mathrm{~T} 1=89,587 \mathrm{~N}
\end{gathered}
$$

\subsubsection{Kecepatan tarik sabuk}

Akibat dari putaran pulley yang terus menerus menyebabkan gaya sentrifugal yang merupakan gaya tegang pada sisi kencang (T1) dan gaya tegangan pada sisi kendur (T2) maka gaya sentrifugal yang terjadi $\left(\mathrm{T}_{\mathrm{c}}\right)$ adalah :

$$
T C=\frac{w-V^{2}}{g}
$$

\section{Ket :}

$\mathrm{TC}=$ gaya sentrifugal $(\mathrm{Kg})$

$\mathrm{W}=$ berat sabuk persatuan panjang $(\mathrm{kg})$

$\mathrm{V}=$ kecepatan linier sabuk $(\mathrm{m} / \mathrm{s})$

$\mathrm{g}$ = gaya gravitasi $\left(\mathrm{m} / \mathrm{s}^{2}\right)$

$\mathrm{W}=\mathrm{A}$. L.$\rho$

Ket :

$$
\begin{aligned}
& A=\text { luas penampang sabuk } \\
& =137,557 \mathrm{~mm}^{2} \\
& =1,37557 \mathrm{~cm}^{2}
\end{aligned}
$$

$\mathrm{L}=$ panjang sabuk

$=1855,075 \mathrm{~mm}$

$=185,5 \mathrm{~cm}$ 
$\rho=$ masa jenis sabuk karet

$=1,14 \mathrm{gr} / \mathrm{cm}^{3}$

Lit 5, hal. 650)

Maka :

$\mathrm{W}=1,37557 \mathrm{~cm}^{2} \times 185,5 \mathrm{~cm} \times 1,14$

$\mathrm{kg} / \mathrm{cm}^{3}$

$$
\begin{aligned}
& =290,891 \mathrm{gr} \\
& =0,290 \mathrm{~kg}
\end{aligned}
$$

Jadi :

$$
\begin{aligned}
\mathrm{TC} & =\frac{0,290 \times(5,582)^{2}}{9,81} \\
& =0,921 \mathrm{~kg} \\
& =0,921.9,81 \\
& =9,036 \mathrm{~N}
\end{aligned}
$$

2.2.2.5 Gaya tegang sisi kencang sabuk :

$\mathrm{T} 1_{\text {maks }}=\mathrm{T} 1+\mathrm{TC} . .($ Lit 5, hal. 672)

$$
\begin{aligned}
& =89,587 \mathrm{~N}+9,036 \mathrm{~N} \\
& =98.623 \mathrm{~N}
\end{aligned}
$$

2.2.2.6 Gaya tegang sisi kendor sabuk :

$$
\begin{aligned}
\mathrm{T} 2_{\text {maks }} & =\mathrm{T} 2+\mathrm{TC} \ldots \ldots \ldots \ldots . . . \\
& =22,766 \mathrm{~N}+9,036 \mathrm{~N} \\
& =31.802 \mathrm{~N}
\end{aligned}
$$

2.2.2.7 Tegangan tarik sabuk :

$$
\begin{aligned}
\sigma_{t} & =\frac{F_{\text {tmaks }}}{A} \\
& =\frac{98.623 \mathrm{~N}}{137,557 \mathrm{~mm}^{2}} \\
& =0,716 \mathrm{~N} / \mathrm{mm}^{2} \\
& =7,298 \mathrm{~kg} / \mathrm{cm}^{2}
\end{aligned}
$$

Tegangan ijin tarik ( ultimate

strength) bahan sabuk berkisar $210 \mathrm{~kg} / \mathrm{cm}^{2}$ sampai $350 \mathrm{~kg} / \mathrm{cm}^{2}$ dan faktor keamanan 8 sampai 10 ( R.S Khurmi, J.K Gupta.1982)

Jadi besar tegangan tarik ijin bahan adalah: $\sigma_{t}=\frac{\sigma_{t}}{v}$

Keterangan :

$\sigma_{i j i n}=$ tegangan ijin sabuk $\left(\mathrm{kg} / \mathrm{cm}^{2}\right)$

$$
=210 \mathrm{~kg} / \mathrm{cm}^{2} \text {.......(Lit 5, hal. 650) }
$$

$v=$ Faktor keamanan

$$
=8
$$

(Lit 5,hal. 650)

$$
\sigma_{i j i n}=\frac{210}{8}
$$$$
=26,25 \mathrm{~kg} / \mathrm{cm}^{2}
$$

Karena $\sigma_{t}<\sigma_{i j i n}$ maka

penggunaan sabuk aman.
2.3 Perhitungan Poros

3.3.1 Poros pada pulley
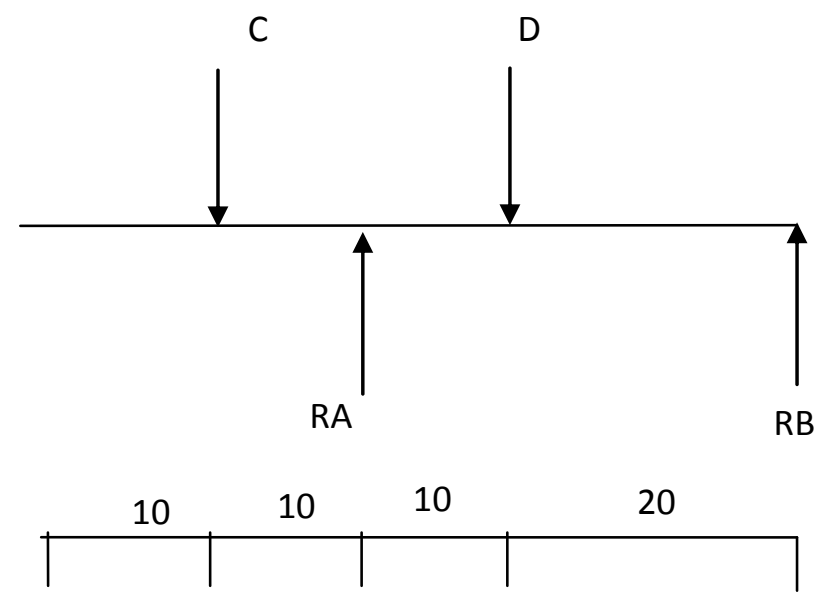

Gambar 2.3 Gaya yang bekerja pada poros pulley dan piringan potong

Ket :

RA : Bearing

$\mathrm{RB}$ : Bearing

C: Pulley $\varnothing 20 "$

$\mathrm{C}_{\mathrm{v}}=1,7 \mathrm{~kg}+(98.623 / 9,81)=11,753$

D: Piringan pisau potong $\emptyset 20 "$

$\mathrm{D}_{\mathrm{v}}=3,2+9,89=13,09 \mathrm{~kg}$

$\Sigma \mathrm{Fx}=0$

$\Sigma \mathrm{Fy}=0$

$\mathrm{RA}+\mathrm{RB}-\mathrm{Cv}-\mathrm{Dv}=0$

$\mathrm{RA}+\mathrm{RB}-11,753-13,09=0$

$\mathrm{RA}+\mathrm{RB}-24,843=0$

$\mathrm{RA}+\mathrm{RB}=24,843$

$\Sigma \mathrm{MRA}=0$

- Cv. $10+$ Dv. $10-$ RB. $30=0$

$-(11,753.10)+(13,09.10)-($ RB. 30$)=0$

$-117,53+130,9-\mathrm{RB} .30=0$

-RB . $30=13,37$

$-\mathrm{RB}=\frac{-13,37}{30}$

$\mathrm{RB}=0,445 \mathrm{~kg}$

$\mathrm{RA}+\mathrm{RB}=24,843$

$\mathrm{RA}+0,445=24,843$

$\mathrm{RA}=24,843-0,445$

$\mathrm{RA}=24,398$ 
2.3.2Momen lentur yang terjadi:

$$
\begin{aligned}
& \mathrm{MRB}=0 \\
& M D v=-(\text { RB. 20) }-(\text { Cv.20 })+(\text { RA.10 }) \\
& =-(0,445.20)-(11,753 \text {. } \\
& 20)+(24,398 \text {. 10). } \\
& =-8,9-235,06+243,98 \mathrm{kgmm} \\
& =0,02 \mathrm{~kg} \\
& \mathrm{MCV}=-(\text { RA.10) }+(\text { Dv.20 })-(\text { RB.30 }) \\
& =-(24,398.10)+(13,09 \cdot 20)- \\
& (0,445.30) \\
& =-243,98+261,8-13,35 \mathrm{kgmm} \\
& =4,47 \mathrm{kgmm} \\
& \text { MRA }=-(\text { Cv.10 })+(\text { Dv.10 })-(\text { RB.30 }) \\
& =-(11,753.10)+(13,09.10)- \\
& (0,445.30) \\
& =-117,53+130,9-13,35 \mathrm{kgmm} \\
& =0,02 \mathrm{kgmm}
\end{aligned}
$$

2.3.3Bahan poros FE360 $=\tau_{B}=37 \mathrm{~kg} / \mathrm{mm}^{2}$

$\mathrm{S} f_{1}=6,0 ; \mathrm{S} f_{2}=2,0$ .(Lit7, hal.8)

$\mathrm{T}=12,476 \mathrm{Nm}=1271,763 \mathrm{kgmm}$

$\tau_{b a}=\frac{37}{(6,0 \times 2,0)}=3,08 \mathrm{~kg} / \mathrm{mm}^{2}$

$\mathrm{K}_{\mathrm{m}}=2,0, \mathrm{~K}_{\mathrm{t}}=1,5$ ...(Lit 7, hal.8 dan 17)

$\mathrm{d}_{\mathrm{s}}$

$=\left[\left(\frac{5,1}{\tau_{a b}}\right) \cdot \sqrt{\left.(K m \times M)^{2}+(K t \times T)^{2}\right)}\right]^{1 / 3}$ (Lit 7, hal 18)

$\mathrm{d}_{\mathrm{s}}$

$=$

$\left[\left(\frac{5,1}{3,08}\right) \cdot \sqrt{\left.(2,0 \times 4,47)^{2}+(1,5 \times 1271,763)^{2}\right)}\right]$

$=13,713 \mathrm{~mm}$..Poros yang dipakai $25,4 \mathrm{~mm}$

2.3.4 Tegangan geser akibat puntir yang terjadi :

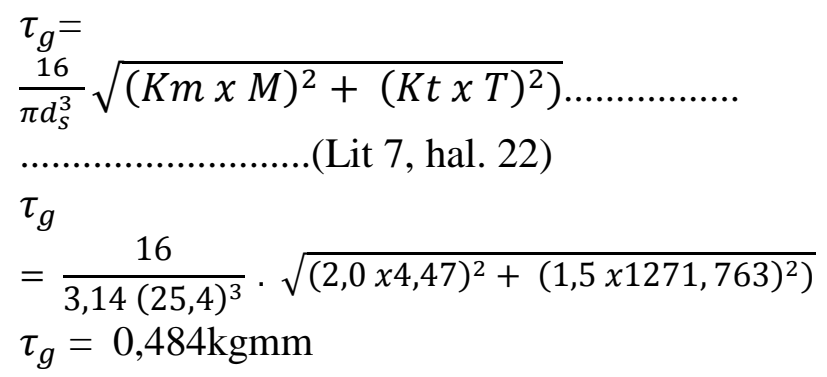

Tegangan geser yang terjadi akibat puntir yang terjadi lebih kecil dari pada tegangan geser izin $(0,484<3,08)$. Maka poros aman terhadap tegangan geser yang terjadi akibat puntir.

2.3.5 Tegangan bengkok yang terjadi :

$$
\sigma_{b}=\frac{32 . M}{\pi d_{s}^{3}} \ldots \ldots \ldots \ldots \ldots . . .(\text { Lit } 7, \text { hal. 17) }
$$

Ket :

$$
\begin{aligned}
\mathrm{M} & =\text { momen } \\
& =4,47 \mathrm{kgmm} \\
\sigma_{b} & =\frac{32 \cdot 4,47}{\pi \cdot 25,4^{3}} \\
& =0,0278 \mathrm{kgmm}^{2}
\end{aligned}
$$

2.3.6 Tegangan bengkok izin :

$\mathrm{Vet}$ : $=$ faktor keamanan bahan 8

$$
\sigma_{i j i n}=\frac{\sigma b}{v}
$$

$$
\begin{aligned}
\sigma_{i j i n} & =\frac{37 \mathrm{~kg} / \mathrm{mm}^{2}}{8} \\
& =7,625 \mathrm{~kg} / \mathrm{mm}^{2}
\end{aligned}
$$

Tegangan bengkok yang terjadi lebih kecil dari pada tegangan bengkok izin $(0,0278<$ 7,625). Maka poros aman terhadap momen bengkok yang terjadi.

\subsection{Perhitungan Bantalan}

Untuk perencanaan ini digunakan jenis bantalan gelinding. Bantalan yang di pakai yaitu bantalan bola radial alur dalam (deep groove ball bearing). Dari spesifikasi bantalan UCP 205-16 untuk diameter $25 \mathrm{~mm}$ diperoleh data-data sebagai berikut : $\mathrm{D}=52 \mathrm{~mm}$ $\mathrm{b}=15 \mathrm{~mm}$

$\mathrm{C}=$ kapasitas nominal dinamis spesifik $1100 \mathrm{~kg}$ $\mathrm{C}_{0}=\mathrm{kapasitas}$ nominal statis spesifik $710 \mathrm{~kg}$

Beban ekuivalen yang diterima oleh bantalan adalah :

$\mathrm{We}=\left(\mathrm{X}_{\mathrm{R}} \cdot \mathrm{V} \cdot \mathrm{W}_{\mathrm{R}}+\mathrm{Y}_{\mathrm{T}} \cdot \mathrm{W}_{\mathrm{T}}\right)$. $\mathrm{K}_{\mathrm{S}}$

(Lit 5, hal. 969) 
Keterangan :

$\mathrm{We}=$ beban ekuivalen yang diterima bantalan

$\mathrm{X}_{\mathrm{R}}=$ faktor beban radial

$=1$

$\mathrm{V}=$ faktor putaran $=1$, untuk bagian dalam yan berputar. (Lit 5, hal.968)

$\mathrm{W}_{\mathrm{R}}=$ beban radial pada bantalan

$\mathrm{Y}_{\mathrm{T}}=$ faktor beban aksial

$=0$

$\mathrm{W}_{\mathrm{T}}=$ beban aksial pada banyalan

$=0$ (tidak ada beban aksial)

$\mathrm{K}_{\mathrm{S}}=$ service faktor beban kejut ringan haganya $=1,5$ (Lit 5, hal. 968)

Kemudian hitung banyaknya putaran pada bantalan karena adanya ekuivalen tersebut, yaitu :

$\mathrm{L}=\left[\frac{\mathrm{C}}{\mathrm{We}}\right]^{k} \cdot 10^{6}$ (Lit 5, hal. 968)

Keterangan :

$\mathrm{L}=$ banyaknya putaran dari bantalan (putaran)

$\mathrm{C}=$ kecepatan dinamis dari bantalan.

$\mathrm{K}=$ faktor jenis bantalan untuk ball bearing

$=3$ (Lit 5, hal. 968)

Umur bantalan :

$\mathrm{L}=60 . \mathrm{n} . \mathrm{LH}$ Lit 5, hal. 968)

Keterangan :

$\mathrm{L} \quad=$ banyak putaran

LH = umur bantalan berdsarkan jam

$\mathrm{n} \quad=$ putaran poros $(\mathrm{rpm})$

\subsubsection{Perhitungan bearing diporos :}

Pada batalan ini bekerja gaya reaksi (RA dan RB), dimana dari perhitungan sebelumnya diketahui nilai RA dan RB, dan harganya adalah sebagai berikut :

$$
\begin{aligned}
& \mathrm{RA}=24,398 \mathrm{~kg} \\
& \mathrm{RB}=0,445 \mathrm{~kg}
\end{aligned}
$$

\section{Maka :}

$$
\begin{aligned}
\mathrm{We} & =\left(\mathrm{X}_{\mathrm{R}} \cdot \mathrm{V} \cdot \mathrm{W}_{\mathrm{R}}+\mathrm{Y}_{\mathrm{T}} \cdot \mathrm{W}_{\mathrm{T}}\right) \cdot \mathrm{K}_{\mathrm{S}} \\
& =(1 \cdot 1 \cdot 24,398+0 \cdot 0) \cdot 1,5 \\
& =36,597 \mathrm{~kg}
\end{aligned}
$$

2.4.2 Banyak putaran bantalan :

$$
\begin{aligned}
\mathrm{L} & =\left[\frac{C}{W e}\right]^{k} \cdot 10^{6} \\
& =\left[\frac{1100}{36,597}\right]^{3} \cdot 10^{6} \\
& =27154,48 \cdot 10^{6}
\end{aligned}
$$

2.4.3 Umur bantalan :

$\mathrm{L}=60 \times n_{2} . \mathrm{LH}$

$\mathrm{LH}=\frac{L}{60 \cdot n}$

$\mathrm{LH}=\frac{27154,48 \cdot 10^{6}}{60 \cdot 332}$

$\mathrm{LH}=1363177,042 \mathrm{jam}$

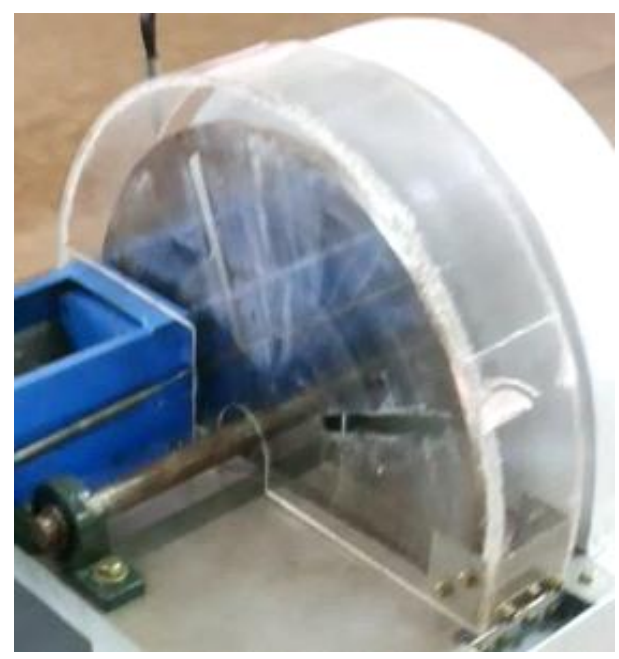

Gambar 2.4 Penutup Mata Pisau

\subsection{KESIMPULAN DAN SARAN KESIMPULAN}

1. perencanaan alat ini adalah untuk mempermudah proses produksi, menghemat waktu pengerjaan, serta menghasilkan produk yang berkualitas. Dalam penggunaan alat bantu pembuat keripik singkong ini mampu memberikan keuntungan dalam jumlah produksi dan juga produk yang dihasilkan memiliki keseragaman yang merata.

2. Dalam perencanaan alat ini, pemilihan bahan merupakan suatu faktor pertimbangan yang sangat penting.

\section{SARAN}

Berdasarkan pembahasan diatas, peneliti dapat memberi saran bahwa penggunaan pengiris keripik singkong ini sangat 
bermanfaat terutama buat industri rumah tangga yang bergerak dibidang pembuatan keripik singkong sehingga kualitas dan jumlah produksi semakin meningkat.

\section{DAFTAR PUSTAKA}

Gerling, Heinrich. 1965. All About Machine Tool. Braunschweig : Georg Westermann Verlag.

Gunawan, Indra dan Fenoria Putri. 2012. Teknologi Mekanik I. Palembang : Teknik Mesin Politeknik Negeri Sriwijaya.

Suparjo. 2014. Modul Sabuk dan Rantai. Palembang : Teknik Mesin Politeknik Negeri Sriwijaya.

Putri, Fenoria. 2013. Teknologi Mekanik II. Palembang : Teknik Mesin Politeknik Negeri Sriwijaya.

R.S. Khurmi. 1982. A Text Book Of Machine Design. New Delhi : Eurasia Publising.

Seprianto, Dicky dan Fatahul Arifin. 2010. Dasar-dasar Solid Modeling Menggunakan Autodesk Inventor. Palembang : Tunas Gemilang Press.

Sularso dan Kiyokatsu Suga. 1991. Dasar Perencanaan dan Pemilihan Elemen Mesin (cetakan kesebelas). Jakarta : PT. Pradnya Paramita. 